\title{
Urgensi Pembelajaran Bahasa Perspektif Al-Qur'an dan Hadits Di Era Disruptif
}

\author{
1* Ikhwan Nur Rois, ${ }^{2}$ Rubini \\ 1 Postgraduate Student of State Islamic University of Raden Mas Said, Surakarta \\ ${ }^{2}$ Lecterur of University of Syuhada Mosque, Yogyakarta \\ E-mail: ${ }^{1 *}$ roisnur04@gmail.com, ${ }^{2}$ rubinihr80@gmail.com
}

Tanggal Submitt: 17/11/2021 Tanggal diterima: 20/11/2021 Tanggal Terbit: 25/12/2021

\begin{abstract}
Abstrak: Canggihnya teknologi yang berkembang pada era Disruptif 4.0 semakin terlihat nyata pada bidang pendidikan. Masuknya era Disruptif menjadi tantangan terhadap dunia pendidikan lebih khusus ilmu bahasa. Tantangan yang terjadi berupa banyak nya masyarakat atau peserta didik yang enggan untuk mempelajari bahasa Al-qur'an dan Hadits. Al-qur'an dan Hadits merupakan pedoman atau landasan utama semua hukum, syari'at bagi manusia, dua pedoman tersebut menjelaskan dengan detail semua yang berkaitan dengan manusia, baik tauhid, kisah-kisah, aturan, perintah dan larangan, termasuk menjelaskan pentingnya pembelajaran bahasa, yang meliputi bahasa Al-qur'an dan Hadits itu sendiri yaitu bahasa Arab , maupun bahasa lainnya. Pada artikel ini akan menjabarkan pentingnya atau urgensi pembelajaran bahasa menurut Al-Qur'an dan Hadits pada era disruptif. Jenis penelitian dalam artikel ini adalah kajian pustaka atau library research, dengan pendekatan deskrptif, metode pengumpulan data yang digunakan adalah metode dokumentasi, data primer pada artikel ini adalah Al-Qur'an dan Hadist, serta didukung pustaka lain yang berkaitan dengan pembahasan. Hasil penelitian adalah bahwa urgensi pembelajaran bahasa menurut Al-qur'an dan Hadits, bahasa yang dimaksud adalah bahasa arab, yaitu: karena bahasa arab merupakan Wahyu Allah, kerena bahasa sebagai alat komunikasi bisa mendalami Al-Qur'an dan Hadist, karena bahasa arab itu disyariatkan oleh Nabi Muhammad Saw untuk di pelajari, bahasa arab sebagai bahasa resmi dunia, dan bahasa arab sebagai alat memahami ilmu-ilmu agama Islam lainnya.
\end{abstract}

Kata kunci: Urgensi, Pembelajaran, Bahasa, Era Disruptif.

\begin{abstract}
Sophisticated technology that developed in the Disruptive 4.0 era is increasingly apparent in the field of education. The entry of the Disruptive era is a challenge to the world of education, more specifically, linguistics. The challenges that occur in the form of many people or students who are reluctant to learn the language of the Qur'an and Hadith. Al-Qur'an and Hadith are guidelines or the main foundation of all laws, sharia for humans, these two guidelines explain in detail all related to humans, both monotheism, stories, rules, commands and prohibitions, including explaining the importance of learning language, which includes the language of the Qur'an and Hadith itself, namely Arabic, as well as other languages. This paper will describe the importance of language learning according to the Qur'an and the Hadith in the disruptive era. This type of research in this paper is a literature study or library research, with a descriptive approach. The data collection method used is the documentation method. The primary data in this paper is the Qur'an and Hadith, and supported by other literature relating to the discussion. The results of the study are that the urgency of language learning according to the Qur'an and the Hadith, the language in question is Arabic, namely: because Arabic is God's Revelation, because language as a communication tool can explore the Qur'an and Hadith, because Arabic it was prescribed by Rasulullah (peace be upon him) to study, Arabic as the official language of the world, and Arabic as a means of understanding other Islamic religious sciences.
\end{abstract}

Keywords: Urgency, Learning, Language, Disruptive Era. 


\section{PENDAHULUAN}

Pada era disruptif ini, begitu pesat berkembangnya alat digital. Dapat kita nikmati alat digital yang canggih tersebut dengan bebas dan leluasa, oleh karena itu alat digital ada yang memberikan dampak positif maupun negatif pada bidang-bidang sosial, agama, keilmuan, ataupun pengetahuan. Dari berbagai dampak yang diberikan, salah satunya dampak negatif yang nyata kita amati yaitu pada bidang pendidikan. Dunia pendidikan sangat luas jika dipaparkan dampak-dampaknya, maka dari itu penulis hanya membatasi dalam lingkup pendidikan bahasa pada artikel ini.

Bahasa saat ini sudah mengalami perubahan yang signifikan dalam hal kaidah, penulisan, media, dan lain sebagainya. Seiring dengan perkembangan zaman yang pesat, maka semakin banyak bahasa-bahasa yang digunakan di dunia ini, diantaranya: bahasa Inggris, bahasa Arab, bahasa mandarin, bahasa Jerman, serta berbagai bahasa di setiap wilayahnya atau negara tertentu. Hal ini cukup dirasakan oleh masyarakat yang sangat peduli dan memperhatikan bahasa dan pembelajarannya, tidak hanya itu bahasa pada era penuh disruptif ini sudah banyak yang tidak diperhatikan ketika menggunakannya.

Berbagai bahasa yang ada di dunia tersebut, ada satu bahasa yang tak kalah penting untuk dipertahankan dan dilestarikan atau dijaga yaitu bahasa yang terkandung didalam al-qur'an dan hadis. Bahasa tersebut di masyarakat luas sudah banyak yang tidak perhatian akan pentingnya belajar bahasa tersebut, lebih khusus pada umat Islam yang mana dengan bahasa tersebut dapat memahami apa-apa yang terkandung didalam alqur'an dan juga hadits Nabi Muhammad nantinya. Oleh karena itu agar dapat dipahami terkait pentingnya bahasa tersebut untuk di pelajari, di jaga dan lain sebagainya, maka dengan alasan diatas, penulis ingin menjelaskan pada artikel ini bahwasanya pentingnya suatu bahasa menurut al-qur'an dan hadits untuk dipelajari pada era disruptif ini.

\section{METODE PENELITIAN}

Pada Penelitian ini, kami menggunakan desain penelitian kualitatif melalui pendekatan deskriptif serta kajian pustaka. Adapun yang kami paparkan pada artikel ini memiliki desain kualitatif diantaranya umum, fleksibel dan dapat berkembang serta muncul dalam proses penelitian. ${ }^{1}$ Menurut Nana penelitian kualitatif adalah suatu penelitian yang ditujukan untuk mendeskripsikan dan menganalisis fenomena, peristiwa, aktivitas sosial, sikap, kepercayaan, persepsi pemikiran orang secara individual maupun kelompok. Serta menurut Sugiyono, penelitian kualitatif adalah penelitian yang berlandaskan pada filsafat postpositivisme, digunakan untuk meneliti pada kondisi obyek yang alamiah, (sebagai lawannya adalah ekperimen) di mana peneliti

${ }^{1}$ Sugiyono, Metode Penelitian Pendidikan: Pendekatan Kuantitatif, Kualitatif, Dan R\&D (Bandung: Alfabeta, 2018). 
adalah sebagai instrument kunci, pengambilan sampel sumber data dilakukan secara purposive dan snowball, teknik pengumpulan data dengan triangulasi (gabungan), analisis data bersifat induktif/kualitatif, dan hasil penelitian kualitatif lebih menekankan makna dari pada generalisasi. ${ }^{2}$

Adapun pendekatan penelitian kami menggunakan pendekatan deskriptif dengan kajian pustaka. Sugiyono menyatakan bahwa metode deskriptif adalah suatu metode yang digunakan untuk menggambarkan atau menganalisis suatu hasil penelitian tetapi tidak digunakan untuk membuat kesimpulan yang lebih luas. ${ }^{3}$ Nazir metode deskriptif merupakan suatu metode dalam meneliti status sekelompok manusia, suatu objek, suatu set kondisi, suatu sistem pemikiran ataupun suatu kelas peristiwa pada masa sekarang. ${ }^{4}$ Tujuan dari penelitian deskriptif ini adalah untuk membuat deskripsi, gambaran, atau lukisan secara sistematis, faktual dan akurat mengenai fakta-fakta, sifat-sifat serta hubungan antarfenomena yang diselidiki. Sedangkan kajian pustaka adalah penelitian yang menjadikan fokus literatur pada buku, jurnal, artikel, atau sumber internet yang sifatnya membantu menguatkan apa yang berkaitan dengan tema artikel kami.

Penulis menggunakan data penelitian deskriptif, yang mana data deskriptif tersebut sangat relevan dig unakan pada penelitian kualitatif. Hal ini selaras dengan Nasution mengatakan bahwa dalam penelitian ini (kualitatif) diusahakan mengumpulkan data deskriptif yang banyak yang dituangkan dalam bentuk laporan dan uraian. ${ }^{5}$ Selain itu dalam pengumpulan data melalui kajian pustaka atau library research, menurut Ratna dalam Prastowo (2012: 80), kajian pustaka memiliki tiga pengertian yang berbeda, diantaranya: ${ }^{6}$ (1) Seluruh bahan bacaan yang mungkin pernah dibaca dan dianalisis, baik yang sudah dipublikasikan maupun sebagai koleksi pribadi. (2) Sering dikaitkan dengan kerangka teori atau landasan teori, yaitu teori-teori yang digunakan untuk menganalisis objek penelitian. (3) Bahan-bahan bacaan yang secara khusus berkaitan dengan objek penelitian yang sedang dikaji.

Adapun menurut Pohan dalam Prastowo kajian pustaka ini bertujuan mengumpulkan data dan informasi ilmiah, berupa teori-teori, metode, atau pendekatan yang pernah berkembang dan telah di dokumentasikan dalam bentuk buku, jurnal,

2 Sugiyono, Metode Penelitian Kualitatif: Untuk penelitian yang bersifat: eksploratif, enterpretif, interaktif, dan konstruktif, (Bandung: Alfabeta, 2017), hlm. 19.

3 Sugiyono, Memahami Penelitian Kualitatif, (Bandung: Alfabeta, 2005), hlm. 21.

${ }^{4}$ Nazir, Metode Penelitian, (Jakarta: Ghalia Indonesia, 1988), hlm. 63.

${ }^{5}$ Nasution, Metode Penelitian Naturalistik Kualitatif, (Bandung; Tarsito, 1992), hlm. 9-10.

${ }^{6}$ Andi Prastowo, Panduan Kreatif Membuat Bahan Ajar Inovatif: Menciptakan Metode Pembelajaran yang Menarik dan Menyenangkan, (Yogyakarta: Diva Press, 2012), hlm. 80. 
naskah, catatan, rekaman sejarah, dokumen-dokumen, dan lain-lain yang terdapat di perpustakaan. ${ }^{7}$

Pada artikel ini, Penulis dalam mengumpulkan data-data melalui kajian pustaka, yang mana data primer penulis yaitu Al-Qur'an dan Hadits-Hadits, adapun untuk datadata sekunder atau penguat, penulis mengambil dari beberapa sumber, diantaranya: perkataan sahabat Nabi Muhammad, buku-buku, artikel, jurnal-jurnal.

Berdasarkan penelitian kualitatif yang kami gunakan, maka pada instrumen penelitian ini, penulis berperan sebagai instrumen utama sebagaimana yang dijelaskan oleh Nasution dalam Sugiyono bahwasanya dalam penelitian kualitatif, tidak ada pilihan lain daripada menjadikan manusia sebagai instrumen penelitian utama. ${ }^{8}$ alasannya ialah bahwa segala sesuatunya belum mempunyai bentuk yang pasti. Masalah fokus penelitian, prosedur penelitian, hipotesis yang digunakan bahkan hasil yang diharapkan itu semuanya tidak dapat ditentukan secara pasti dan jelas sebelumnya. segala sesuatu masih perlu dikembangkan sepanjang penelitian itu. Dalam keadaan yang serba tidak pasti dan tidak jelas itu, tidak ada pilihan lain dan hanya peneliti itu sendiri sebagai alat satu-satunya yang dapat mencapainya. ${ }^{9}$ Menurut Moleong Kedudukan peneliti dalam penelitian kualitatif adalah ia sekaligus merupakan perencana, pelaksana, pengumpulan data, analisis, penafsir data, pada akhirnya ia menjadi pelapor hasil penelitiannya, selain penulis menjadi instrumen utama juga diperlukan instrumen dari Al-Qur'an dan hadits, perkataan sahabat Nabi Muhammad, buku catatan, buku-buku, jurnal dan lainnya. ${ }^{10}$

Pada penelitian kualitatif tahap teknis analisis data ini merupakan bagian yang sangat sulit dilakukan bagi para peneliti dikarenakan belum adanya metode analisis yang dirumuskan dengan baik hal tersebut diterangkan oleh Miles and Huberman (1984) dalam buku Sugiyono. Disisi lain Susan Stainback menyatakan "There are no guidelines in qualitative research for determining have much data and data analysis are necessary to support and assertion, conclusion, or theory". Yang artinya: Belum ada panduan dalam penelitian kualitatif untuk menentukan berapa banyak data dan analisis yang diperlukan untuk mendukung kesimpulan atau teori. Menurut Andi (2014: 45) Analisis data dalam penelitian kualitatif dilakukan secara terus-menerus dari awal hingga akhir penelitian; dengan induktif; dan mencari pola, model, tema, serta teori. ${ }^{11}$

\footnotetext{
7 Ibid., hlm. 81

8 Sugiyono, Metode Penelitian Administrasi, (Bandung: Alfabeta, 1998).

${ }^{9}$ Sugiyono, Metode Penelitian Pendidikan:Pendekatan Kuantitatif, Kualitatif, dan R\&D. (Bandung: Alfabeta, 2018)

10 Moleong, Lexy J., Metodologi Penelitian Kualitatif. Edisi Revisi, (Bandung: PT Remaja Rosdakarya, 2007), hlm. 168.

11 A. Prastowo, Metode Penelitian Kualitatif: Dalam Perspektif Rancangan Penelitian. (Yogyakarta: Ar-Ruzz Media, 2014.)
} 
Berdasarkan hal di atas bahwa analisis data ini bersifat induktif, yaitu suatu analisis berdasarkan data yang diperoleh, selanjutnya dikembangkan pola hubungan tertentu atau menjadi hipotesis. Oleh karena itu, penulis menggunakan analisis data secara individu pada artikel ini.

Prosedur penelitian kualitatif ini memiliki sifat induktif, yang mana berawal dari sebuah kejadian di lapangan (empirical social reality), sehingga terbangun grounded theory, selanjutnya berkembang menjadi subtantive theory, midle-range theory, formal theory, dan akhirnya menjadi tehoretical frame work (also call paradigm or theoritical system). Berbeda dengan prosedur penelitian kuantitatif yang bersifat dekdutif, sebuah proses yang berawal dari tehoretical frame work sesuatu yang bersifat abstrak, difokuskan dengan subtantive theory, midle-range theory, formal theory, selanjutnya dirumuskan hipotesis untuk diuji sehingga menuju ke empirical social reality atau kejadian-kejadian yang konkrit. Sebagai gambaran prosedur penelitian, kami berikan gambar prosedurnya dibawah ini:
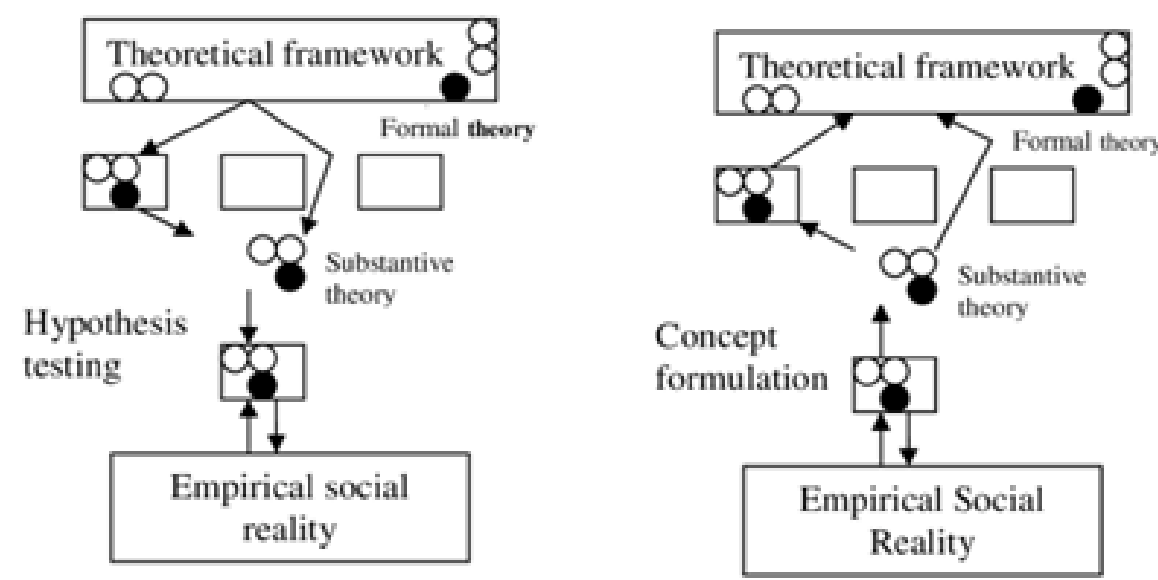

Deductive process

Inductive process

Gambar 1. Deductive and Inductive Theorizing

\section{PEMBAHASAN}

a. Pembelajaran Bahasa

1. Definisi Bahasa

Definisi Bahasa menurut sebagian pakar linguistik, diantaranya: Soenjono Dardjowidjojo menyebutkan bahwa bahasa adalah suatu sistem simbol lisan yang arbitrer yang dipakai oleh anggota suatu masyarakat bahasa untuk berkomunikasi dan berinteraksi antar sesamanya, 
berlandaskan pada budaya yang mereka miliki bersama. ${ }^{12}$ Gorys Keraf mengatakan bahwa bahasa merupakan alat komunikasi sosial yang berupa sistem simbol bunyi yang dihasilkan dari ucapan manusia. ${ }^{13}$ Bahasa adalah alat untuk berinteraksi dengan orang lain dan sebagai alat bantu berpikir. Bahasa erat hubungannya dengan budaya mengingat bahasa erat kaitannya dengan pola pikir suatu masyarakat. Artinya, bahasa memegang peranan yang sangat penting di dalam proses berpikir dan kreativitas. Bahasa bersifat simbolis, artinya suatu kata mampu melambangkan arti apapun. ${ }^{14}$ Kridalaksana (1983) mengatakan bahwa bahasa adalah sistem lambang yang arbitrer yang dipergunakan oleh suatu masyarakat untuk bekerja sama, berinteraksi, dan mengidentifikasi diri.

Berdasarkan beberapa teori diatas, maka dapat kami simpulkan bahwasanya bahasa memiliki arti sebagai alat komunikasi sosial yang bersifat simbolis sehingga setiap manusia dapat menggunakan bahasa yang berbedabeda pada lingkungan masyarakat tertentu.

2. Sifat Bahasa

Bahasa itu sendiri memiliki beberapa sifat didalamnya, seperti: a) Sistematik, (b) Mana suka, sebagaimana yang dijelaskan oleh Santoso, dkk (2004) disebut bahasa mana suka ialah unsur-unsur bahasa dipilih secara acak tanpa dasar. Tidak ada hubungan logis antara bunyi dan makna yang disimbolkannya, (c) Ujar, (d) Manusiawi,(e) Komunikatif. 15

3. Fungsi Bahasa

Pada umumnya, bahasa memiliki fungsi sebagai alat komunikasi baik secara lisan maupun tulisan. Dengan bahasa kita dapat menjalin komunikasi antara sesama manusia, bahkan kita dapat mengetahui makna atau maksud bahasa dari ucapan objek kita. Diantara fungsi bahasa sebagai alat komunikasi lainnya, seperti: (a) fungsi informasi, (b) fungsi ekspresi diri, (c) fungsi adaptasi dan integrasi, dan (d) fungsi kontrol sosial (Santoso, dkk). Sedangkan menurut Hallyday (1992) fungsi bahasa sebagai alat komunikasi adalah (a) Fungsi Instrumental, (b) Fungsi Regulatoris, (c) Fungsi Intraksional, (d) Fungsi Personal, (e) Fungsi Heuristik, (f) Fungsi Imajinatif, (g) Fungsi Representasional.

12 M. T. Aziz, "Asal Usul Bahasa Dalam Perspekif Al-Qur'an \& Sains Modern," Utile J. Kependidikan, vol. 02, no. 02, hlm. 125-146, 2016

${ }^{13}$ G. Keraf, Komposisi: Sebuah Pengantar Kemahiran Bahasa. (Jakarta: Nusa Indah, 1997)

14 U. Khair, "Pembelajaran Bahasa Indonesia \& Sastra (BASASTRA) di SD dan MI," Riayah, vol. 02, no. 01, hlm. 81-98, 2018

${ }^{15}$ B. Sagendra, Belajar \& Pembelajaran Bahasa Indonesia. (Semarang: Linggayoni Publishing, 2014) 


\section{Pembelajaran Bahasa}

Pembelajaran adalah proses interaksi peserta didik dengan pendidik dan sumber belajar pada suatu lingkungan belajar baik lingkungan pendidikan formal maupun nonformal. ${ }^{16} \mathrm{Hal}$ ini berarti bahwa pembelajaran bahasa merupakan suatu aktifitas yang dilakukan oleh pendidik dan peserta didik pada suatu lingkungan belajar bahasa dengan memanfaatkan sumbersumber belajar yang relevan dan mengacu pada kurikulum yang berlaku. Sedangkan tujuan pembelajaran bahasa, menurut Basiran (1999) adalah keterampilan komunikasi dalam berbagai konteks komunikasi. Kemampuan yang dikembangkan adalah daya tangkap makna, peran, daya tafsir, menilai, dan mengekspresikan diri dengan berbahasa.

Adapun maksud penulis dalam artikel ini, untuk memaparkan pembelajaran bahasa menurut al-qur'an dan hadits ialah pembelajaran bahasa Arab. Selanjutnya kami akan memaparkan bahwasanya pentingnya pembelajaran bahasa Arab tersebut menurut sumber primer yang kami gunakan pada penelitian ini.

\section{b. Bahasa Menurut Al-Qur'an dan Hadits}

\section{Al-Qur'an}

Beberapa ayat-ayat dari al-qur'an yang kami paparkan berkaitan dengan pentingnya bahasa, diantaranya: 17

a) Q.S. Az-Zukhruf: 03

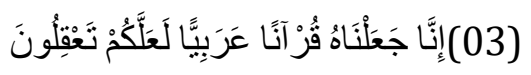

Artinya: "Sesungguhnya Kami menjadikan Al Quran dalam bahasa Arab supaya kamu memahaminya".

Berdasarkan ayat diatas, Tafsir Al-Mukhtashar / Markaz Tafsir Riyadh, di bawah pengawasan Syaikh Dr. Shalih bin Abdullah bin Humaid, menjelaskan makna yang terkandung didalamnya: Yakni Allah menurunkannya dengan bahasa Arab, karena setiap nabi diberi kitab dengan bahasa kaumnya. Dan Kami jadikan al-Qur'an itu berbahasa arab agar kalian dapat memahaminya hai orang-orang Arab, dan mengerti makna dan kandungannya, karena ia

16 B. D. Pusat Kurikulum, Pelaksanaan Kurikulum Berbasis Kompetensi. (Jakarta: Balitbang Depdiknas, 2002)

17 "Tafsirweb." 
menggunakan bahasa yang sangat fasih yang menerangkan maksud kandungannya dan mudah dipahami.

b) QS. Az-Zumar: 27-28

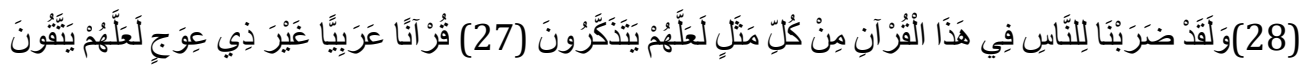

Artinya: "Sesungguhnya telah Kami buatkan bagi manusia dalam Al-Qur'an ini setiap macam perumpamaan supaya mereka dapat pelajaran(27). (Ialah) AlQur'an dalam bahasa Arab yang tidak ada kebengkokan (di dalamnya) supaya mereka bertakwa (Ialah) Al Quran dalam bahasa Arab yang tidak ada kebengkokan (di dalamnya) supaya mereka bertakwa (28)".

Berdasarkan ayat diatas, Tafsir Al-Mukhtashar / Markaz Tafsir Riyadh, di bawah pengawasan Syaikh Shalih bin Abdullah bin Humaid, menjelaskan makna yang terkandung didalamnya: Yakni dengan segala perumpamaan yang mereka butuhkan untuk urusan agama mereka. Agar kalian mengambil ibrah dan pelajaran. Al Quran dalam bahasa Arab Yakni dengan bahasa arab yang jelas dan tidak mengandung perselisihan dan pertentangan, dan keraguan di dalamnya. Pendapat lain mengatakan bahwa di dalamnya tidak terdapat kesalahan secara Bahasa.

c) Q.S. Asy-Syu'ara: 192-195

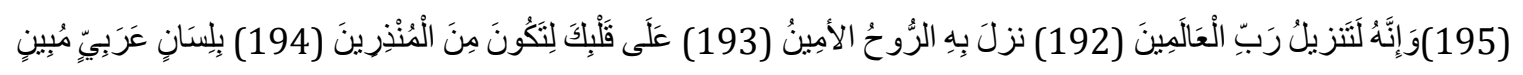

Artinya: "Dan sesungguhnya Al-Qur'an ini benar-benar diturunkan oleh Tuhan semesta alam (192), dia dibawa turun oleh Ar-Ruhul Amin (Jibril) (193), ke dalam hatimu (Muhammad) agar kamu menjadi salah seorang di antara orangorang yang memberi peringatan (194), dengan bahasa Arab yang jelas (195).

Berdasarkan ayat diatas, Tafsir Al-Mukhtashar / Markaz Tafsir Riyadh, di bawah pengawasan Syaikh Dr. Shalih bin Abdullah bin Humaid, menjelaskan makna yang terkandung didalamnya: Allah menjadikan al-Qur'an memakai bahasa Arab sesuai dengan bahasa Rasul yang merupakan orang Arab agar orang-orang musyrik tidak mengatakan "kami tidak dapat memahami apa yang kamu katakan selain bahasa kami” sehingga al-Qur'an yang berbahasa Arab ini dapat memotong alasan mereka dan membantah hujjah mereka.

d) Q.S. Ar-Ra'du: 37

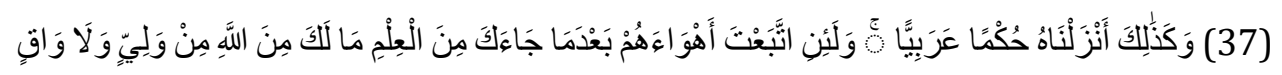


Artinya: "Dan demikianlah, Kami telah menurunkan Al Quran itu sebagai peraturan (yang benar) dalam bahasa Arab. Dan seandainya kamu mengikuti hawa nafsu mereka setelah datang pengetahuan kepadamu, maka sekali-kali tidak ada pelindung dan pemelihara bagimu terhadap (siksa) Allah".

Berdasarkan ayat diatas, Tafsir Al-Mukhtashar / Markaz Tafsir Riyadh, di bawah pengawasan Syaikh Dr. Shalih bin Abdullah bin Humaid, menjelaskan makna yang terkandung didalamnya: yakni Kami turunkan al-Qur'an yang mengandung asas-asas dan perincian syariat dengan menggunakan bahasa arab, sebagaimana Kami turunkan kitab-kitab yang lain kepada para rasul dengan bahasa mereka. supaya mereka harap agar kamu mengikutinya. Apaapa Yang diajarkan Allah kepadamu. Allah Yang mengatur urusanmu dan menolongmu. Dan Melindungimu dari azab-Nya.

e) Q.S. An-Nahl: 103

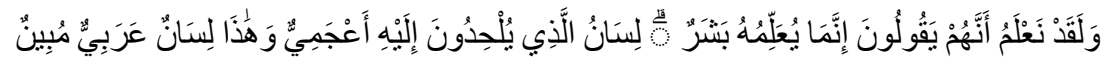

Artinya: "Dan sesungguhnya Kami mengetahui bahwa mereka berkata: "Sesungguhnya Al Quran itu diajarkan oleh seorang manusia kepadanya (Muhammad)". Padahal bahasa orang yang mereka tuduhkan (bahwa) Muhammad belajar kepadanya bahasa 'Ajam, sedang Al Quran adalah dalam bahasa Arab yang terang".

Berdasarkan ayat diatas, Tafsir Al-Mukhtashar / Markaz Tafsir Riyadh, di bawah pengawasan Syaikh Dr. Shalih bin Abdullah bin Humaid, menjelaskan makna yang terkandung didalamnya: Yakni Kami sungguh mengetahui bahwa orang-orang kafir itu berkata "sebenarnya orang yang mengajarkan Muhammad al-Qur'an adalah seorang manusia dan bukan malaikat". Orang tersebut menurut pengakuan mereka adalah budak milik Fakih bin Mughirah yang bernama Jabar, dulunya ia beragama Nasrani kemudian masuk Islam. Bahasa orang yang mereka anggap sebagai orang yang menajarkanmu alQur'an adalah bahasa 'ajam yang tidak memiliki kefasihan. Al-Qur'an yang memiliki kefasihan tinggi dan penjelasan yang jelas. kalian mengatakan bahwa orang yang mengajarkannya al-Qur'an itu berasal dari kaum 'ajam, sedangkan kalian sendiri tidak mampu menandingi salah satu surat dalam al-Qur'an, padahal kalian adalah ahli kefasihan dan raja dalam ilmu balaghah; bagaimana kalian bisa mengatakan tuduhan ini? 
f) Q.S. Asy-Syura: 07

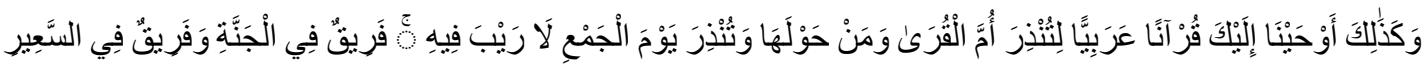

Artinya: "Demikianlah Kami wahyukan kepadamu Al Quran dalam bahasa Arab, supaya kamu memberi peringatan kepada ummul Qura (penduduk Mekah) dan penduduk (negeri-negeri) sekelilingnya serta memberi peringatan (pula) tentang hari berkumpul (kiamat) yang tidak ada keraguan padanya. Segolongan masuk surga, dan segolongan masuk Jahannam".

Berdasarkan ayat diatas, Tafsir Al-Mukhtashar / Markaz Tafsir Riyadh, di bawah pengawasan Syaikh Dr. Shalih bin Abdullah bin Humaid, menjelaskan makna yang terkandung didalamnya: Yakni dengan bahasa kaummu, sebagaimana Kami mengutus setiap rasul dengan agama kaumnya, yakni kota Makkah. Dan yang dimaksud adalah agar Rasulullah memberi peringatan kepada penduduk kota Makkah agar kamu memperingatkan mereka dari azab hari kiamat. Sebab hari itu sebagai waktu dikumpulkannya para makhluk dan dikumpulkannya antara arwah dengan tubuhnya. Yakni tanpa ada keraguan, mereka semua akan berkumpul di padang mahsyar kemudian saling berpisah sesuai dengan tempat yang ditentukan bagi mereka.

g) Q.S. Al-Ahqaf: 12

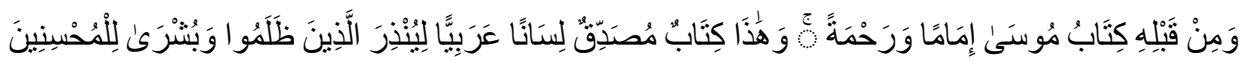

Artinya: "Dan sebelum Al Quran itu telah ada kitab Musa sebagai petunjuk dan rahmat. Dan ini (Al Quran) adalah kitab yang membenarkannya dalam bahasa Arab untuk memberi peringatan kepada orang-orang yang zalim dan memberi kabar gembira kepada orang-orang yang berbuat baik".

Berdasarkan ayat diatas, Tafsir Al-Mukhtashar / Markaz Tafsir Riyadh, di bawah pengawasan Syaikh Dr. Shalih bin Abdullah bin Humaid, menjelaskan makna yang terkandung didalamnya: yakni kitab Musa, yaitu Taurat yang mendahului al-Qur'an. Dua kitab ini sesuai dalam asas-asas syari'at, hal ini menunjukkan bahwa al-Qur'an adalah benar dan berasal dari Allah Yang menjadi pedoman dalam agama, dan ia adalah rahmat Allah bagi orang yang mengimaninya. Al Quran adalah kitab yang membenarkannya, ialah membenarkan kitab Musa yang merupakan petunjuk dan rahmat, dan juga membenarkan kitab-kitab Allah yang lain serta menggunakan bahasa Arab yang mereka pahami. Untuk memperingatkan (kalian) dari azab Allah, 
sehingga tidak ada alasan lagi bagi mereka. Dan kesudahan mereka adalah kemenangan dan surga sebagai balasan kebaikan mereka.

2. Hadits

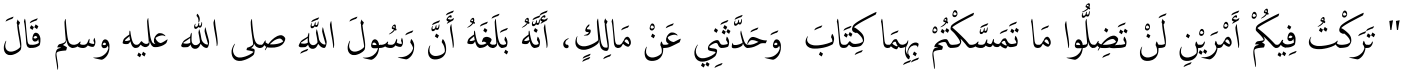

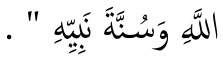

Artinya: Dari Malik, sesungguhnya ia telah menyampaikan kepadanya bahwasanya Nabi Muhammad bersabda: "Aku tinggalkan sesuatu bersama kalian, jika kamu berpegang teguh padanya, kalian tidak akan tersesat selamalamanya yaitu Kitabullah dan Sunnahku." (HR.Imam Malik dalam AlMuwaththa' 2/899)

a) Imam Asy-Syafi'i rahimahullah mengatakan,

$$
\text { ... فعلى كل مسلم أن يتعلم من لسان العرب ما بلغه بجده حتى يشهـ به أن لا إله إلا الله وأن محمد عبده ورسوله ويتلوا به كتاب الله }
$$

"Maka wajib atas setiap muslim untuk mempelajari bahasa Arab sekuat kemampuannya. Sehingga dia bersaksi bahwa sesungguhnya tidak ada sesembahan yang berhak disembah kecuali Allah Ta'ala dan Muhammad adalah hamba dan utusan-Nya, dan dengannya dia bisa membaca kitabullah ..."

b) Syaikhul Islam Ibnu Taimiyah rahimahullah berkata,

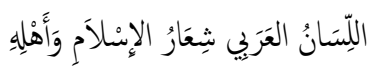

"Bahasa Arab adalah syi'ar Islam dan syi'ar kaum muslimin." Disebutkan dalam Iqtidha' Shirath Al-Mustaqim.

c) Ibnu Katsir saat menjelaskan surat Yusuf ayat kedua menyatakan,

$$
\text { لأن لغة العرب أفصح اللغات وأبينها وأوسعها، وأكرها تأدية للمعاني التي تقوم بالنفوس }
$$

"Karena bahasa Arab adalah bahasa yang paling fasih, paling jelas, paling luas (kosakatanya), dan paling banyak mengandung makna yang menentramkan jiwa."

d) Ibnu Katsir rahimahullah juga menyatakan,

$$
\text { فلهذا أنزل أشرف الكتب بأشرف اللفات، على أشرف الرسل، بسفارة أشرف الملايكة، وكان ذلك في أشرف بقاع الأرض، وابتدئ إنزاله في أشرف }
$$


“Karena Al-Qur'an adalah kitab yang paling mulia, diturunkan dengan bahasa yang paling mulia, diajarkan pada Rasul yang paling mulia, disampaikan oleh malaikat yang paling mulia, diturunkan di tempat yang paling mulia di muka bumi, diturunkan pula di bulan yang mulia yaitu bulan Ramadhan. Dari berbagai sisi itu, kita bisa menilai bagaimanakah mulianya kitab suci AlQur'an."

Berdasarkan sumber rujukan primer tersebu, yaitu Al-Qur'an dan Hadits serta dikuatkan dengan perkataan Sahabat Nabi Muhammad, maka dapat kita simpulkan bahasa arab merupakan suatu disiplin ilmu yang penting untuk dipelajari bagi setiap umat beragama Islam.

\section{A) Urgensinya Bahasa Arab}

Penulis telah memaparkan diatas tentang dalil-dalil atau ayat-ayat yang menjelaskan betapa pentingnya pembelajaran bahasa menurut al-qur'an dan hadits, pada poin yang terpenting ini, maka penulis memaparkan sungguh pentingnya (urgent) Bahasa Arab itu sendiri untuk umat agama Islam pelajari, diantaranya:

1) Karena bahasa arab merupakan wahyu Allah

Al-Qur'an merupakan mukjizat Allah, mukjizat ialah wahyu yang Allah turunkan kepada Nabi Muhammad SAW, yang mana Allah menurunkan Al-Qur'an tersebut dengan bahasa Arab, maka karena itu bahasa Arab juga menjadi wahyu Allah yang diturunkan kepada Nabi Muhammad SAW. Hal ini dibuktikan pada firman Allah dalam Surah Asy-Syura: 07, yang artinya: "Demikianlah Kami wahyukan kepadamu Al Quran dalam bahasa Arab, supaya kamu memberi peringatan kepada ummul Qura (penduduk Mekah) dan penduduk (negeri-negeri) sekelilingnya serta memberi peringatan (pula) tentang hari berkumpul (kiamat) yang tidak ada keraguan padanya. Segolongan masuk surga, dan segolongan masuk Jahannam".

2) Karena bahasa sebagai alat komunikasi bisa mendalami Al-Qur'an dan Hadist Al-Qur'an dan Hadits merupakan sumber pedoman kehidupan manusia dan keduanya menggunakan bahasa Arab, maka dari itu bahasa Arab berperan sebagai alat komunikasi agar bisa mendalami kedua pedoman manusia, selaras dengan firman Allah dalam surah Az-Zukhruf: 03, yang artinya: "Sesungguhnya Kami menjadikan Al Quran dalam bahasa Arab supaya kamu memahaminya".

3) Karena bahasa arab itu disyariatkan oleh Nabi Muhammad saw untuk di pelajari Setiap syariat atau ajaran yang Nabi Muhammad SAW tinggalkan kepada para pengikutnya, wajib untuk dilaksanakan dan ditaati. Berkaitan dengan itu bahasa 
Arab menjadi hal yang urgent atau disyariatkan Nabi Muhammad SAW untuk dipelajari. Hal ini sesuai dengan hadits Nabi Muhammad SAW, yang artinya: "Aku tinggalkan sesuatu bersama kalian, jika kamu berpegang teguh padanya, kalian tidak akan tersesat selama-lamanya yaitu Kitabullah dan Sunnahku."

4) Karena bahasa arab sebagai bahasa resmi dunia

Dirilis oleh Perserikata Bangsa-Bangsa atau yang kita kenal dengan PBB. PBB saat ini memiliki enam bahasa resmi, yaitu Inggris, Arab, Tionghoa, Prancis, Rusia, dan Spanyol yang digunakan dalam pertemuan antar pemerintah, dan pembuatan dokumen-dokumen. ${ }^{18}$ Bahasa Arab digunakan sebagai bahasa resmi negara di 26 negara di dunia. Bahasa Arab ditetapkan sebagai bahasa resmi dunia oleh UNESCO PBB pada tanggal 18 Desember 1973 sebagai hari bahasa Arab sedunia, dengan adanya penetapan dari UNESCO, maka mempelajari bahasa Arab menjadi sesuatu yang urgent di dunia pendidikan internasional.

5) Karena bahasa arab sebagai alat memahami ilmu-ilmu agama Islam lainnya Diantara Ilmu-ilmu agama, seperti: Fikih,Aqidah, Akhlak, Tafsir, Tauhid, dan lainnya. Itu semua pastinya menggunakan satu sumber, yang mana sumber tersebut menggunakan bahasa Arab, maka dari itu bahasa Arab salah satu menjadi urgent untuk dipelajari dan dipahami bagi orang-orang yang ingin memahami ilmu-ilmu agama lainnya tersebut. Sebagaimana Umar bin Khatab mengatakan: "Pelajarilah bahasa Arab, karena Bahasa ini begian dari agama kalian".

\section{KESIMPULAN}

Berdasar uraian diatas, dapat disimpulkan bahwa bahasa menurut Al-Qur'an dan Hadits ialah bahasa Arab. Dalam artikel ini telah dipaparkan penulis tentang metodologi penelitiannya, dan pembahasan seputar bahasa Arab yang terkandung pada Al-Qur'an, Hadits maupun perkataan para Sahabat Nabi Muhammad SAW. Berdasarkan teori-teori yang ada pada artikel ini, maka dapat kita ketahui bahwasanya bahasa menurut AlQur'an dan Hadits atau yang dikenal bahasa Arab ini sangatlah urgent untuk dipelajari dan dipahami, diantara bentuk dari urgent nya tersebut ialah: karena bahasa arab merupakan Wahyu Allah, kerena bahasa sebagai alat komunikasi bisa mendalami $\mathrm{Al}$ Qur'an dan Hadist, karena bahasa arab itu disyariatkan oleh Nabi Muhammad saw untuk di pelajari, bahasa arab sebagai bahasa resmi dunia, dan bahasa arab sebagai alat memahami ilmu-ilmu agama Islam lainnya.

18 “Wikipedia (Peserikatan Bangsa-bangsa)." 31-Okt-2019 


\section{DAFTAR PUSTAKA}

Andi Prastowo. 2012. Panduan Kreatif Membuat Bahan Ajar Inovatif: Menciptakan Metode Pembelajaran yang Menarik dan Menyenangkan. Yogyakarta: Diva Press.

Andi Prastowo. 2014. Metode Penelitian Kualitatif: Dalam Perspektif Rancangan Penelitian. Yogyakarta: Ar-Ruzz Media.

B. D. Pusat Kurikulum. 2002. Pelaksanaan Kurikulum Berbasis Kompetensi. Jakarta: Balitbang Depdiknas

B. Sagendra. 2014. Belajar \& Pembelajaran Bahasa Indonesia. Semarang: Linggayoni Publishing

G. Keraf. 1997. Komposisi: Sebuah Pengantar Kemahiran Bahasa. Jakarta: Nusa Indah

Moleong, Lexy J. 2007. Metodologi Penelitian Kualitatif. Edisi Revisi. Bandung: PT. Remaja Rosdakarya.

M. T. Aziz. 2016. “Asal Usul Bahasa Dalam Perspekif Al-Qur'an \& Sains Modern,” Utile J. Kependidikan, vol. 02, no. 02, hlm. 125-146, 2016

Nasution. 1992. Metode Penelitian Naturalistik Kualitatif. Bandung; Tarsito.

Nazir. 1988. Metode Penelitian. Jakarta: Ghalia Indonesia.

Sugiyono. 1998. Metode Penelitian Administrasi. Bandung: Alfabeta.

Sugiyono. 2005. Memahami Penelitian Kualitatif. Bandung: Alfabeta.

Sugiyono. 2017. Metode Penelitian Kualitatif: Untuk Penelitian Yang Bersifat: Eksploratif, Enterpretif, Interaktif, Dan Konstruktif. Bandung: Alfabeta.

Sugiyono. 2018. Metode Penelitian Pendidikan: Pendekatan Kuantitatif, Kualitatif, Dan $R \& D$. Bandung: Alfabeta

U. Khair. 2018. "Pembelajaran Bahasa Indonesia \& Sastra (BASASTRA) di SD dan MI," Riayah, vol. 02, no. 01, hlm. 81-98, 2018 